\title{
MODELAGEM AMBIENTAL DE BACIAS HIDROGRÁFICAS: CARACTERIZAÇÃO MORFOMÉTRICA E PEDOLÓGICA DA BACIA DO RIO UNA - IBIÚNA, BRASIL
}

Elfany Reis do Nascimento Lopes ${ }^{1}$

José Carlos de Souza ${ }^{2}$ Jocy Ana Paixão de Sousa ${ }^{3}$ José Luiz Albuquerque Filho ${ }^{4}$ Roberto Wagner Lourenço ${ }^{5}$

Resumo: O estudo objetivou descrever a modelagem ambiental avaliando os parâmetros morfométricos e pedológicos da bacia hidrográfica do rio Una, Ibiúna, São Paulo, utilizando técnicas de geoprocessamento em ambiente SIG. A avaliação dos parâmetros hidrológicos e morfométricos foram determinados a partir de rotinas de processamento nos módulos Surface, Hidrology e Integrated Water Management. Os parâmetros pedológicos de textura e matéria orgânica foram avaliados pelo método da pipeta e combustão. A bacia estende-se por $96 \mathrm{~km}^{2}$, com forma irregular e alongada, não sujeita a enchentes, altitude média de 937 metros e cota máxima de 1175 metros. O relevo é fortemente ondulado, com declividade média de $18 \%$. Os solos apresentam tendência a textura arenosa e menos siltosa e matéria orgânica entre 10 a $60 \%$.

Palavras-chave: Geoprocessamento; Morfometria; Recursos Hídricos; Avaliação Ambiental; Bacia Hidrográfica

\section{ENVIRONMENTAL MODELING OF RIVER BASINS: MORPHOMETRIC AND PEDOLOGICAL CHARACTERIZATION OF THE UNA BASIN - IBIÚNA, BRAZIL}

\begin{abstract}
The study aimed to describe the environmental modeling by evaluating the morphometric and pedological parameters of the river basin of the Una river, in the southeast of Brazil, using geoprocessing techniques in a GIS environment.The evaluation of the hydrological and morphometric parameters were determined from processing routines in the Surface, Hydrology and Integrated Water Management modules. The pedological parameters of texture and organic matter were evaluated by the pipette and combustion method. The basin extends over $96 \mathrm{~km}^{2}$, with irregular and elongated shape, not subject to flooding, average altitude of 937 meters and maximum elevation of 1175 meters. The relief is strongly undulating, with an average slope of $18 \%$. The soils present a tendency to sandy texture and less silt and organic matter between 10 to $60 \%$.
\end{abstract}

Keywords: Geoprocessing. Morphometry; Hydric Resources; Environmental Assessment; Basin.

\footnotetext{
${ }^{1}$ Biólogo. Mestre em Meio Ambiente. Doutorando em Ciências Ambientais pela Universidade Estadual Paulista. Bolsista Novos Talentos do Instituto de Pesquisas Tecnológicas. Email: elfany@ posgrad.sorocaba.unesp.br

${ }^{2}$ Geógrafo. Doutor em Ciências Ambientais. Professor da Universidade Estadual de Goiás. Email: jose.souza@ueg.br

${ }^{3}$ Engenheira Florestal. Mestre em Ciências Ambientais. Email: jocypet@gmail.com

${ }^{4}$ Geólogo. Doutor em Geociências e Meio Ambiente. Pesquisador do Instituto de Pesquisas Tecnológicas de São Paulo. Email: albuzelu@ipt.br

${ }^{5}$ Geógrafo. Doutor em Geociências e Meio Ambiente. Professor Titular da Universidade Estadual Paulista. Instituto de Ciência e Tecnologia de Sorocaba. Email: robertow@sorocaba.unesp.br
} 


\section{MODELIZACIÓN AMBIENTAL DE CUENCAS HIDROGRÁFICAS: CARACTERIZACIÓN MORFOMÉTRICA Y PEDOLÓGICA DE LA CUENCA DE UNA - IBIÚNA, BRASIL}

Resumen: El estudio objetivó describir el modelado ambiental evaluando los parámetros morfométricos y pedológicos de la cuenca hidrográfica del río Una, Ibíúna, São Paulo, utilizando técnicas de geoprocesamiento en ambiente SIG. La evaluación de los parámetros hidrológicos y morfometricos se determinó a partir de rutinas de procesamiento en los módulos Surface, Hidrology e Integrated Water Management. Los parámetros pedológicos de textura y materia orgánica fueron evaluados por el método de la pipeta y la combustión. La cuenca se extiende por $96 \mathrm{~km}^{2}$, con forma irregular y alargada, no sujeta a inundaciones, altitud media de 937 metros y cuota máxima de 1175 metros. El relieve es fuertemente ondulado, con declividad media de $18 \%$. Los suelos presentan tendencia a textura arenosa y menos siltosa y materia orgánica entre 10 a $60 \%$.

Palabras clave: Geoprocesamiento; Morfometría; Recursos Hidráulicos; Evaluación Ambiental; Cuenca Hidrografía

\section{INTRODUÇÃO}

As características do sistema de drenagem de uma bacia hidrográfica são importantes informações para a execução de medidas de conservação da terra e da água, permitindo orientar a adoção de ações sobre o planejamento ambiental (AHER; ADINARAYANA; GORANTIWAR, 2014). As bacias hidrográficas são estudadas levando em consideração a sua drenagem e seus parâmetros geológicos, geomorfológicos, pedológicos, químicos, vegetais e antrópicos, conferindo a importância de investigar a sua estrutura e as interações na qual ela encontra-se delimitada (MAGESH et al., 2013).

Estudos primários já colocavam a análise de bacias hidrográficas como critério importante para investigar processos hidrológicos, sendo a análise morfométrica uma forma quantitativa de caracterização de uma bacia (NAUTIYAL, 1994; STRAHLER, 1957). A análise morfométrica consiste de uma descrição detalhada do sistema de drenagem, fornecendo subsídios para a compreensão da influência da morfometria no relevo com base no estudo do tamanho, forma, declividade, densidade de drenagem, tamanho e comprimento dos cursos d'água (MAGESH et al., 2013; STRAHLER, 1957).

De forma semelhante, a análise pedológica é essencial para traçar o planejamento do uso do solo, inclusive para a recuperação de áreas degradadas. Estudos nesta linha vêm apresentando relações diretas entre a textura do solo com a mudança na paisagem, vegetação e 
influência na declividade, principalmente em horizontes superficiais (BABU; SREEKUMAR; ASLAM, 2016; MULUGETA; SHELEME, 2010; SHELEME, 2011).

No contexto da análise espacial, o geoprocessamento e o Sistema de Informação Geográfica (SIG) são ferramentas que têm combinado uma gama de parâmetros ambientais, devido a capacidade de reportar resultados confiáveis durante a avaliação de dados temáticos. Ambos são considerandos ferramentas potenciais para avaliar, determinar e interpretar a análise de informações ambientais relacionadas ao espaço geográfico das bacias hidrográficas (BABU; SREEKUMAR; ASLAM, 2014; MAGESH; CHANDRASEKAR; KALIRAJ, 2012).

Essas observações podem ser feitas com base em estudos realizados em todo o mundo, seja no estudo de Mesa et al. (2006) em análise morfométrica em Bacias da Argentina, Magesh et al. (2013) e Babu, Sreekumar e Aslam (2014), que utilizaram a análise espacial para descrever a morfométrica de bacias hidrográficas na Índia ou o de Ferrrari et al. (2013) e Costa e Silva (2016), que tem combinado análise morfométrica e a avaliação do uso do solo para traçar perfis de conservação ambiental de bacias hidrográficas utilizando o SIG.

Considerando a importância dos estudos nesta linha e das bacias hidrográficas para o contexto da conservação dos atributos hídricos, físicos e bióticos, o presente estudo objetivou descrever a modelagem ambiental avaliando os parâmetros morfométricos e pedológicos da bacia hidrográfica do rio Una, Ibiúna, São Paulo, utilizando técnicas de geoprocessamento em ambiente SIG.

A região apresenta importância ambiental por encontrar-se inserida no bioma Mata Atlântica, com a sua cabeceira próxima à importante Unidades de Conservação do Estado de São Paulo, dentre elas a Área de Proteção Ambiental (APA) da Serra do Mar, APA de Corumbataí, Botucatu e Tejupá e a APA do Itupararanga. Além disso, o rio Una é um imporante componente do sistema hídrico regional, contribuindo significativamente para o Reservatório de Itupararanga, principal fonte de abastecimento de água para a região de Ibiúna e Sorocaba. 


\section{METODOLOGIA}

\section{Localização e características da área de estudo}

O estudo foi desenvolvido na bacia hidrográfica do rio Una, localizada em sua totalidade no município de Ibiúna e pertencente a Décima Unidade de Gerenciamento de Recursos Hídricos do Sorocaba e Médio Tietê (UGHRI 10), na região sudeste do Estado de São Paulo (Figura 1).
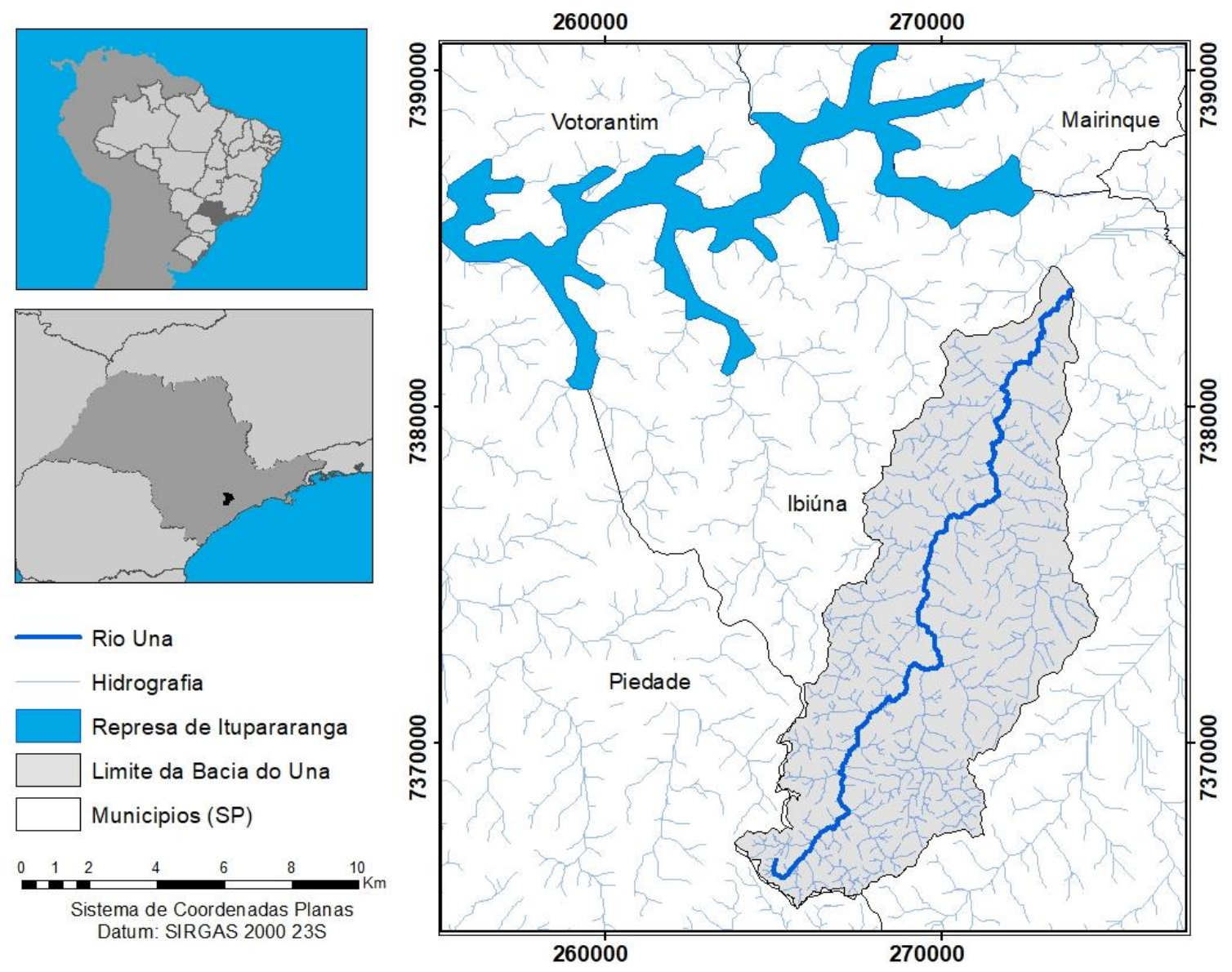

Datum: SIRGAS $200023 \mathrm{~S}$

Figura 1: Localização da Bacia do rio Una, Ibiúna, São Paulo.

O rio Una recebe águas do córrego do Cupim, ribeirão do Leopoldo e ribeirão do Salto, desaguando no rio Sorocabuçu, principal afluente para a formação do reservatório de Itupararanga. O clima da bacia é definido como $\mathrm{Cwb}$, de acordo com a classificação de Köppen, com verão chuvoso (janeiro) e estiagem de inverno (agosto) (KÖPPEN, 1931). O período úmido apresenta o mês de janeiro com a maior média de precipitação $(242 \mathrm{~mm})$ e o 
período seco tem agosto o mês com a menor precipitação (34 mm) (CIIAGRO, 2015). A bacia apresenta uma zona de transição entre rural e urbana, abrigando parte da área urbana do município de Ibiúna e áreas agrícolas que caracterizam a principal atividade econômica do município.

\section{Análise morfométrica}

Para a análise morfométrica da bacia foi delimitado o Modelo Digital do Terreno (MDT) através do método TIN (Triangular Irregular Networks), com base nas curvas de nível e pontos cotados extraídos da base cartográfica da área de estudo. O TIN é compreendido como uma estrutura vetorial, com topologia do tipo nó-arco, que representa a morfologia da superfície através das características do relevo e da drenagem por meio de faces triangulares interligadas, contendo coordenadas de localização (x, y) e um atributo z, correspondente a elevação ou altitude (AGGIDIS; BENZON, 2013; CÂMARA et al., 1999; ESRI, 2014).

Para a obtenção das cartas de declividade e orientação do terreno utilizou-se o MDT, procedendo a rotina de processamento através dos módulos slope e aspect, no software ArcGis (ESRI, 2014). A declividade é baseada na proporção entre desníveis e suas respectivas distâncias horizontais, que podem ser expressas em graus $\left(0^{\circ}\right.$ a $\left.90^{\circ}\right)$ ou em porcentagem $(0 \%$ a infinito) (VALERIANO; ALBUQUERQUE, 2010). Neste estudo, adotou-se a classificação da Empresa Brasileira de Produção Agropecuária (EMBRAPA), conforme Tabela 1 (EMBRAPA, 2006).

Tabela 1: Classes de declividade

\begin{tabular}{c|c}
\hline Intervalo (\%) & Tipo de declividade no relevo \\
\hline $0-3 \%$ & Relevo plano \\
\hline $3-8 \%$ & Relevo suavemente ondulado \\
\hline $8-20 \%$ & Relevo ondulado \\
\hline $20-45 \%$ & Relevo forte ondulado \\
\hline $45-75 \%$ & Relevo montanhoso \\
\hline$>75 \%$ & Relevo escarpado \\
\hline
\end{tabular}

Fonte: EMBRAPA (2006). 
A orientação do terreno considera a orientação da declividade de um determinado ponto no terreno, definida pela direção transversal às curvas de nível e no sentido descendente, acompanhando o fluxo esperado do escoamento superficial (ESRI, 2014; VALERIANO; ALBUQUERQUE, 2010). A orientação do terreno foi fatiada em classes através da reclassificação dos graus de orientação conforme a Tabela 2.

Tabela 2: Classes de orientação do terreno

\begin{tabular}{c|c}
\hline Intervalo (graus) & Orientação da declividade \\
\hline 0 & Exposições a norte \\
\hline Até 22,5 & Exposições a nordeste \\
\hline$>22,5$ até 67,5 & Exposições a leste \\
\hline$>67,5$ até 112,5 & Exposições a sudeste \\
\hline$>112,5$ até 157,5 & Exposições a sul \\
\hline$>157,5$ até 202,5 & Exposições a sudoeste \\
\hline$>202,5$ até 247,5 & Exposições a oeste \\
\hline$>247,5$ até 292,5 & Exposições a noroeste \\
\hline$>292,5$ até 337,5 & Exposições a norte \\
\hline \multicolumn{2}{c}{ Fonte: ESRI (2014). }
\end{tabular}

A caracterização geométrica da bacia e da rede de drenagem foi realizada para os parâmetros descritos nas Tabelas 3 e 4. Os parâmetros foram calculados através de rotinas de geoprocessamento com os módulos Hydrology no software ArcGis 10.3 e do Integrated Water Management no Idrisi Selva, utilizando como dados de entrada o MDT e o limite da bacia hidrográfica (CLARK LABS, 2012; ESRI, 2014).

Tabela 3: Características geométricas

\begin{tabular}{|c|c|}
\hline $\begin{array}{l}\text { CARACTERÍSTICAS } \\
\text { GEOMÉTRICAS }\end{array}$ & DEFINIÇÃO \\
\hline Área total da bacia (A) & $\begin{array}{l}\text { Área delimitada pelo divisor de águas a partir da somatória das } \\
\text { áreas do limite da bacia. }\end{array}$ \\
\hline Perímetro total da bacia $(\mathrm{P})$ & $\begin{array}{l}\text { Comprimento médio ao longo do divisor de águas estimado a } \\
\text { partir do do limite da bacia, segundo a somatória de todas as } \\
\text { diagonais. }\end{array}$ \\
\hline Comprimento da bacia (L) & Comprimento da foz até o exutório da bacia. \\
\hline Largura da bacia & $\begin{array}{l}\text { Largura entre os lados da bacia, considerando a orientação } \\
\text { oeste - leste. }\end{array}$ \\
\hline
\end{tabular}




\begin{tabular}{|c|c|}
\hline Altitude média da bacia & $\begin{array}{l}\text { Representa a variação da elevação média do terreno da bacia } \\
\text { com referência ao nível médio do mar. }\end{array}$ \\
\hline Declividade média & Inclinação média que atinge o terreno da bacia. \\
\hline $\begin{array}{l}\text { Coeficiente de } \\
\text { compacidade }(\mathrm{Kc})\end{array}$ & $\begin{array}{l}\text { Relaciona a forma da bacia com um círculo, definido como a } \\
\text { relação entre perímetro da bacia e a circunferência de um } \\
\text { círculo de área igual à da bacia. Sendo: } \mathrm{Kc}=1=\text { circular } \\
\text { (VILLELA; MATTOS 1975). } \\
\qquad \mathrm{KC}=0,28 \times \mathrm{P} / \sqrt{A} \\
\text { Onde: } \\
\mathrm{KC}=\text { Coeficiente de compacidade } \\
\mathrm{P}=\text { Perímetro } \\
\mathrm{A}=\text { Área de drenagem }\end{array}$ \\
\hline Índice de circularidade (Ic) & $\begin{array}{l}\text { Relaciona a forma da bacia com a forma circular. Sendo: Ic }=1 \\
=\text { circular (TONELLO et al., 2006). } \\
\qquad \mathrm{IC}=(12,57 \times \mathrm{A}) / \mathrm{P}^{2} \\
\text { Onde: } \\
\mathrm{IC}=\text { Índice de circularidade } \\
\mathrm{A}=\text { Área de drenagem em } \mathrm{km}^{2} \\
\mathrm{P}=\text { Perímetro em } \mathrm{km}\end{array}$ \\
\hline Fator de forma (Kf) & $\begin{array}{l}\text { Relaciona a forma da bacia com a forma de um retângulo. É } \\
\text { determinado pela relação entre a largura média e o } \\
\text { comprimento do curso d'água principal. Sendo: Kf }=1= \\
\text { retangular (VILLELA; MATTOS 1975). } \\
\qquad \mathrm{KF}=\mathrm{A} / \mathrm{L}^{2} \\
\text { Onde: } \\
\mathrm{KF}=\text { Fator de forma; } \\
\mathrm{A}=\text { Área de drenagem } \\
\mathrm{L}=\text { comprimento do eixo da bacia }\end{array}$ \\
\hline
\end{tabular}

Tabela 4: Características da rede de drenagem

\begin{tabular}{l|l}
\hline $\begin{array}{c}\text { CARACTERÍSTICAS } \\
\text { DA REDE DE } \\
\text { DRENAGEM }\end{array}$ & \multicolumn{1}{c}{ DEFINIÇÃO } \\
\hline Ordem dos cursos & $\begin{array}{l}\text { Classificação que reflete o grau de ramificação ou bifurcação } \\
\text { dentro de uma bacia (STRAHLER, 1957). }\end{array}$ \\
\hline $\begin{array}{l}\text { Comprimento total dos } \\
\text { cursos d'água }\end{array}$ & $\begin{array}{l}\text { Medida em planta da nascente até a seção de referência de cada } \\
\text { tributário e curso principal, através da reclassificação da } \\
\text { hidrografia em ordens específicas segundo a somatória das } \\
\text { diagonais de suas células. }\end{array}$ \\
\hline $\begin{array}{l}\text { Comprimento do curso } \\
\text { d'água principal }\end{array}$ & $\begin{array}{l}\text { Comprimento do curso d'água principal medido em planta, } \\
\text { desde a nascente até a seção exutória da bacia. }\end{array}$ \\
\hline $\begin{array}{l}\text { Comprimento direto do } \\
\text { curso principal }\end{array}$ & $\begin{array}{l}\text { Comprimento direto do curso d'água principal medido em } \\
\text { planta, desde a nascente até a seção exutória da bacia }\end{array}$ \\
\hline
\end{tabular}




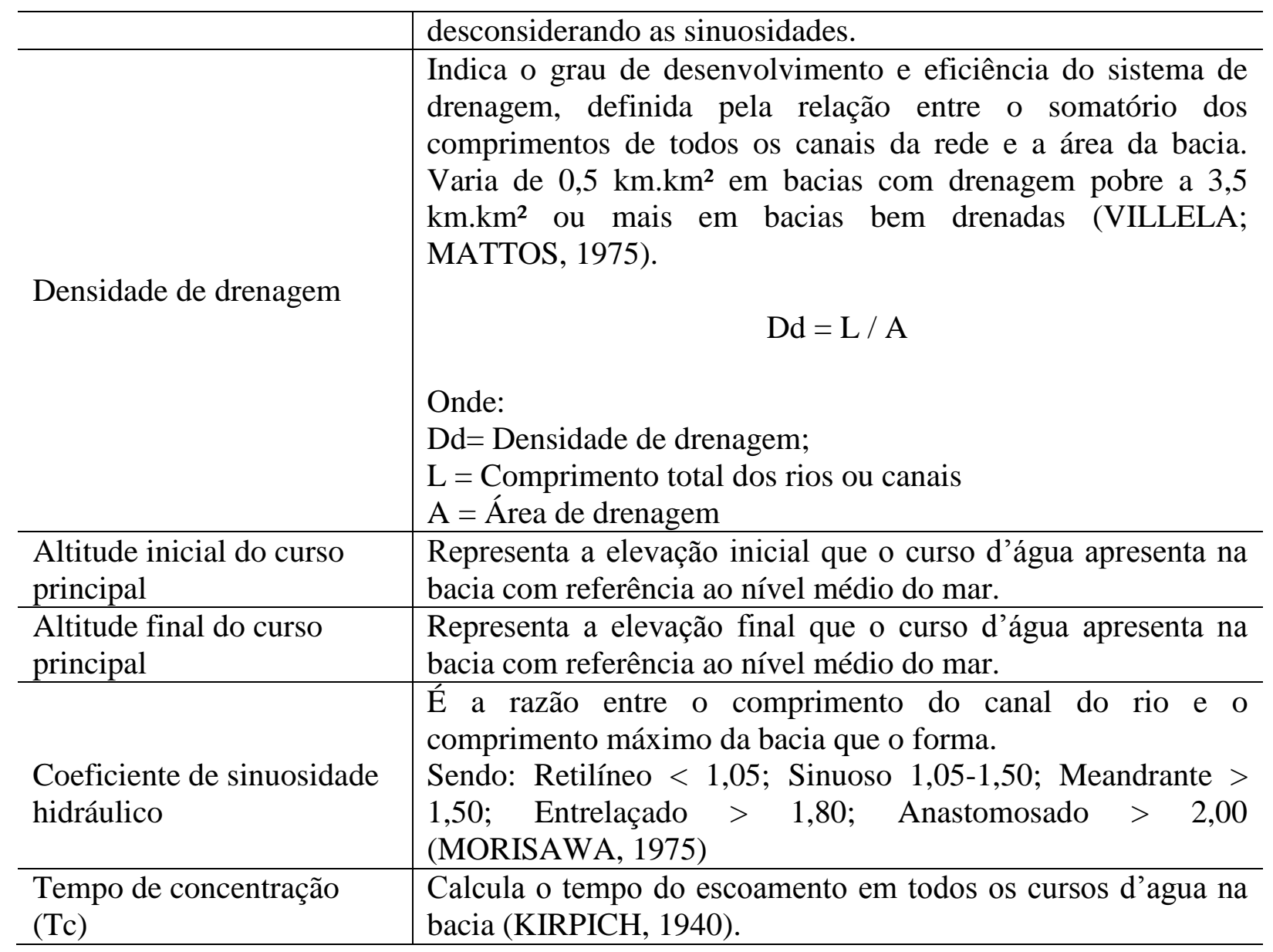

\section{Análise pedológica}

A caracterização do solo foi realizada com base no mapa pedológico do Estado de São Paulo (OLIVEIRA, 1999). A adaptação da carta de solos para a área da bacia foi realizada através da intersecção das informações espaciais ao limite da bacia hidrográfica. Considerando que a escala do mapeamento de solos existente não possui uma escala a nível de detalhe, e compativel com a área da bacia, o estudo do solo baseou-se também na análise da textura do solo e da matéria orgânica, visando caracterizá-lo detalhadamente.

As etapas de textura e matéria orgânica foram procedidas de coletas de 35 amostras de solos, conforme uma malha amostral irregular que considerou os diferentes tipos de uso do solo e cobertura vegetal da bacia (Figura 2). As amostras foram coletadas com trado na profundidade 0-20 cm, retiradas 500 gramas de solo, sendo embalado e identificado para análise em laboratório. 


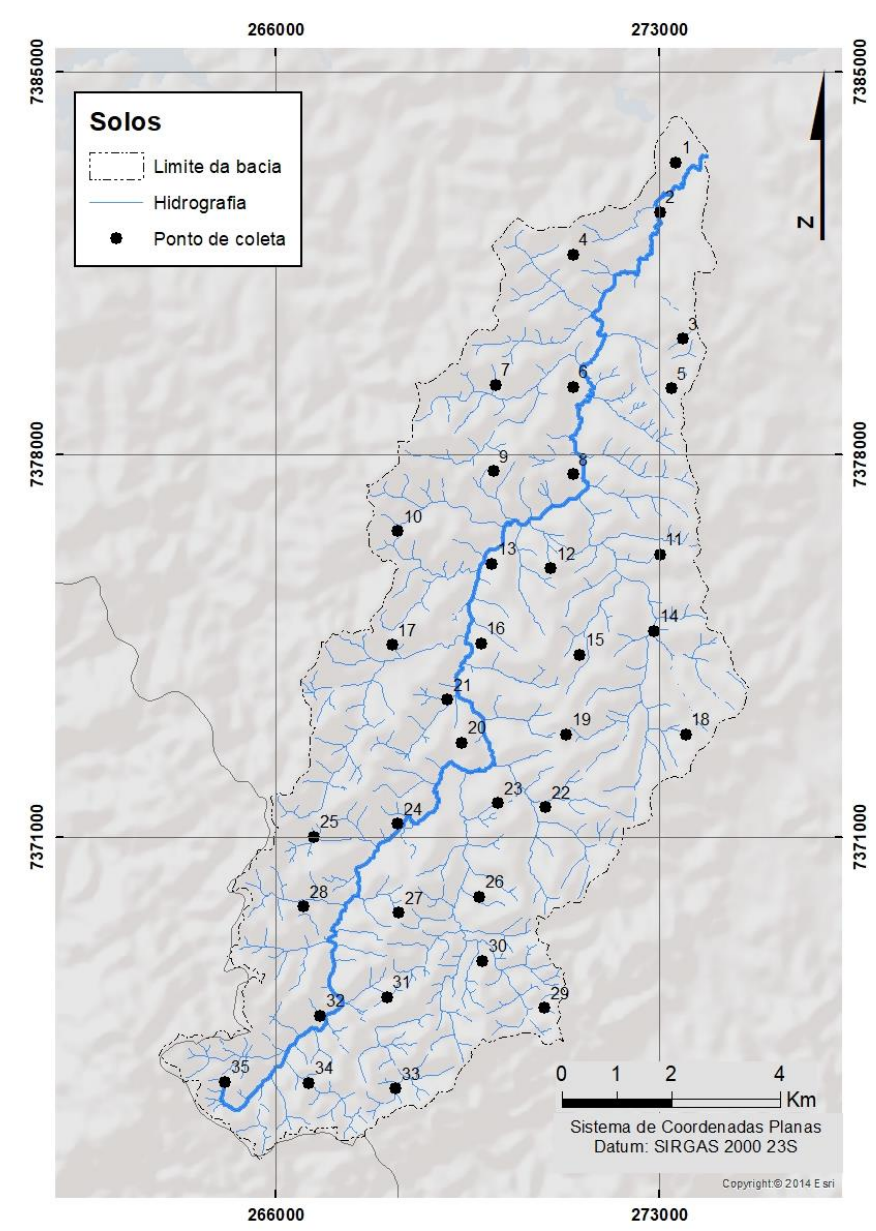

Figura 2: Malha amostral de coleta de solos na Bacia do rio Una, Ibiúna, São Paulo.

A análise textural foi realizada pelo método da pipeta na terra fina seca ao ar (TFSA), segundo metodologia do Instituto Agronômico de Campinas (IAC). Utilizou-se a solução dispersante de hidróxido e hexametasfofato de sódio, com agitação por 16 horas em agitador rotatório de Wagner. As frações de areia foram definidas em peneira de 0,2 $\mathrm{mm}$ e as frações de argila e silte separadas por pipeta em períodos de sedimentação (IAC, 2009).

A matéria orgânica foi analisada, utilizando o método de combustão proposto pelo IAC, visando avaliar o teor de matéria orgânica através da combustão em mufla, comparando o valor inicial e final do peso amostral (IAC, 2009). Foi aplicada a interpolação Spline para a espacialização das texturas de solo da bacia. 


\section{RESULTADOS E DISCUSSÃO}

O MDT apresentado na Figura 3 demostra a amplitude hipsométrica da Bacia com intervalos variando de 50 em 50 metros.

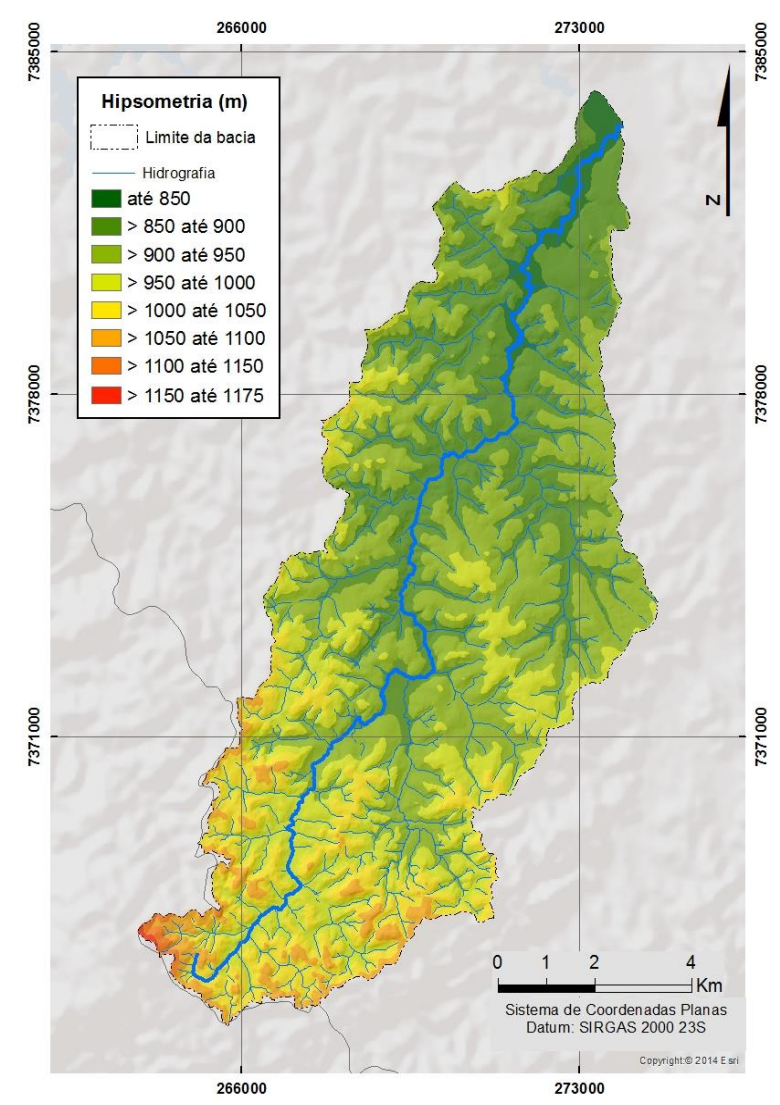

Figura 3: Hipsometria da Bacia do rio Una, Ibiúna, São Paulo.

A porção sul apresenta as maiores cotas altimétricas com valores de até 1175 metros, enquanto os pontos mais distantes em direção ao exutório atingem altitudes correspondentes a 850 metros. Cerca de $54 \%$ da área da bacia encontra-se representada por cotas altimétricas entre 900 a $1000 \mathrm{~m}$, enquanto as cotas mais altas (> $1150 \mathrm{~m}-1175 \mathrm{~m}$ ) e baixas (até $850 \mathrm{~m}$ ) representam as menores áreas com 0,06 e 2,85\%, respectivamente (Tabela 5).

A curva hipsométrica pode ser observada na Figura 4 com a demonstração da altitude máxima de 1175m, média de 937 metros e mínima de 850m. A curva confirma também, a distribuição hipsométrica apresentada na Tabela 5, onde 50\% da área da bacia encontram-se em altitude igual ou superior a 937 metros. 
Tabela 5: Quantificação das áreas hipsométricas da Bacia do rio Una, Ibiúna, São Paulo

\begin{tabular}{c|c|c}
\hline Hipsometria $(\mathbf{m})$ & Área (ha) & Área (\%) \\
\hline Até 850 & 275,35 & 2,85 \\
\hline$>850-900$ & 2610,70 & 27,07 \\
\hline$>900-950$ & 3357,01 & 34,81 \\
\hline$>950-1000$ & 1899,53 & 19,70 \\
\hline$>1000-1050$ & 1097,96 & 11,38 \\
\hline$>1050-1100$ & 360,30 & 3,73 \\
\hline$>1100-1150$ & 34,45 & 0,35 \\
\hline$>1150-1175$ & 5,85 & 0,06 \\
\hline
\end{tabular}

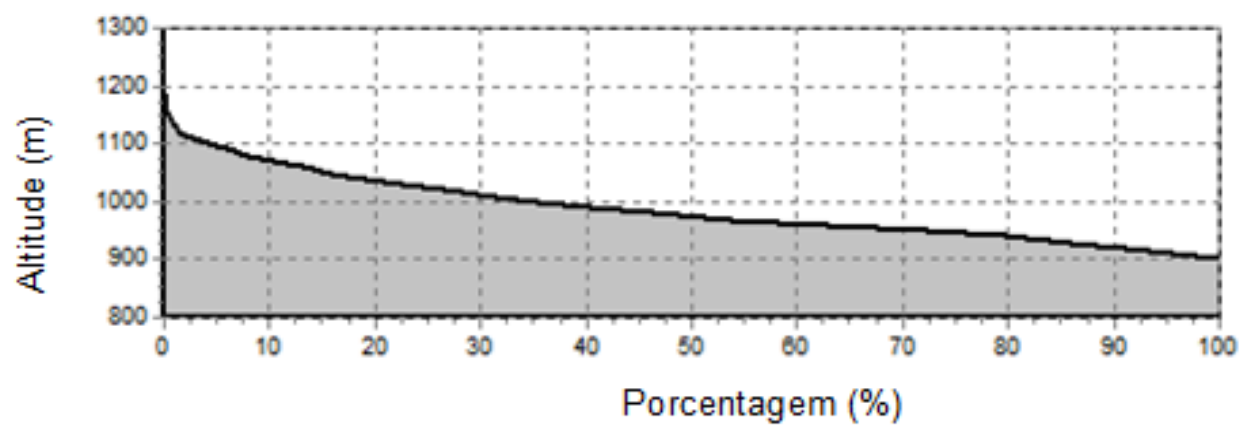

Figura 4: Curva hipsométrica da Bacia do rio Una, Ibiúna, São Paulo.

A Figura 5 apresenta as áreas de declividade e a Tabela 6 os valores de área de cada intervalo de declividade. O relevo ondulado é predominante, correspondendo as áreas que apresentam declive acima de $20 \%$ e seguem até os $45 \%$. 


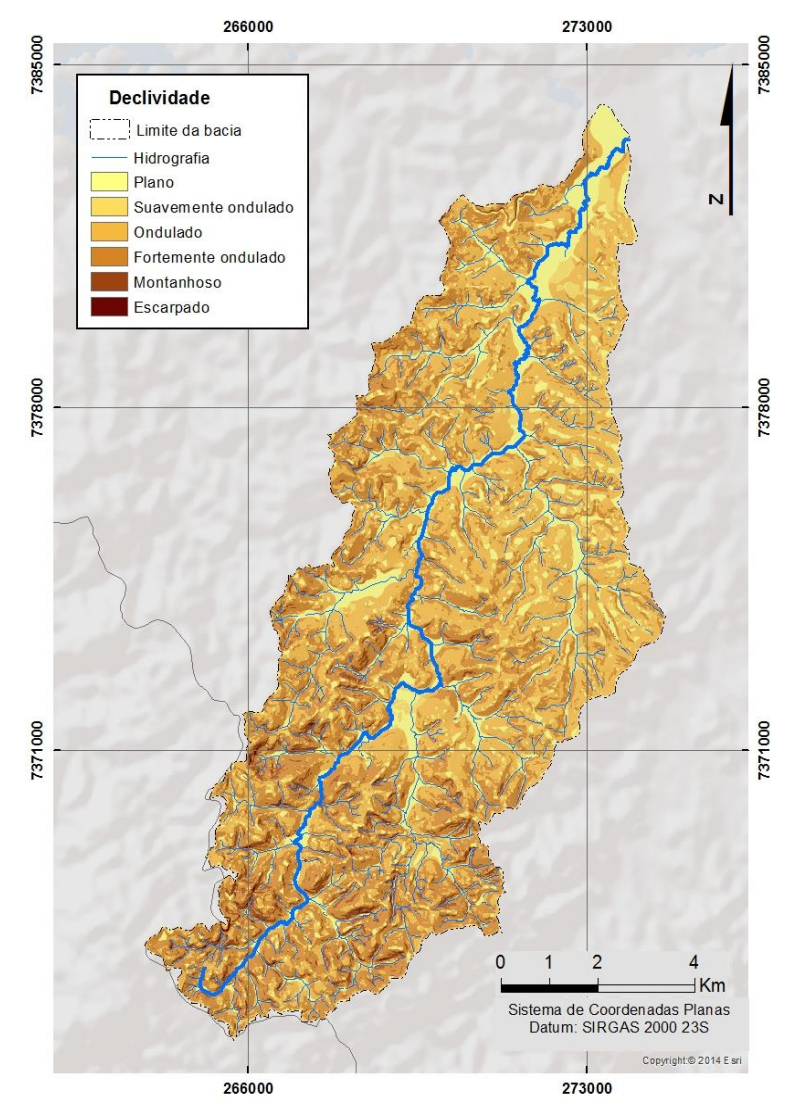

Figura 5: Declividade da Bacia do rio Una, Ibiúna, São Paulo.

Tabela 6: Quantificação das áreas de declividade da Bacia do rio Una, Ibiúna, São Paulo

\begin{tabular}{l|l|c|c}
\hline \multicolumn{1}{c|}{ Declividade (\%) } & \multicolumn{1}{|c|}{ Situação do relevo } & Área (ha) & Área (\%) \\
\hline Até 3 & Plano & 1342,59 & 13,93 \\
\hline$>3$ até 8 & Suavemente ondulado & 673,16 & 6,98 \\
\hline$>8$ até 20 & Ondulado & 3959,33 & 41,07 \\
\hline$>20$ até 45 & Fortemente ondulado & 3295,57 & 34,18 \\
\hline$>45$ até 75 & Montanhoso & 353,35 & 3,67 \\
\hline$>75$ & Escarpado & 16,42 & 0,17 \\
\hline
\end{tabular}

Áreas pontuais ao norte são classificadas com declividade acima de $45 \%$, assim como as áreas já declivosas ao sul, que juntas representam 3,87\% de todo o território da bacia. $\mathrm{O}$ conhecimento da declividade da bacia hidrográfica auxilia no cumprimento da legislação, do manejo e a gestão dos recursos hídricos, especificamente do mapeamento de águas subterrâneas, do planejamento adequado do uso do solo e a prevenção à perda de solo (MAGESH et al., 2013; MOGHADDAM et al. 2015; TONELLO et al., 2006).

$\mathrm{Na}$ bacia, os relevos montanhoso e escarpado apresentam áreas isoladas de declive acima de $45 \%$ ou $75 \%$ ao sul (Figura 4). A perda de solo em bacias hidrográficas estão associadas com os maiores níveis de declividade, e apesar destas áreas representarem os 
menores percentuais de declive, estudos aprofundamentos são necessários para a confirmação dessa occorência (MAGESH et al., 2013).

A Figura 6 apresenta a orientação das vertentes do terreno da bacia. Na Tabela 7 é apresentado o quantitativo de área para cada orientação do terreno. É possível afirmar que há uma predominância de terreno orientado ao norte $(13,80 \%)$, noroeste $(12,90 \%)$, seguida da orientação para o nordeste $(12,14 \%)$.

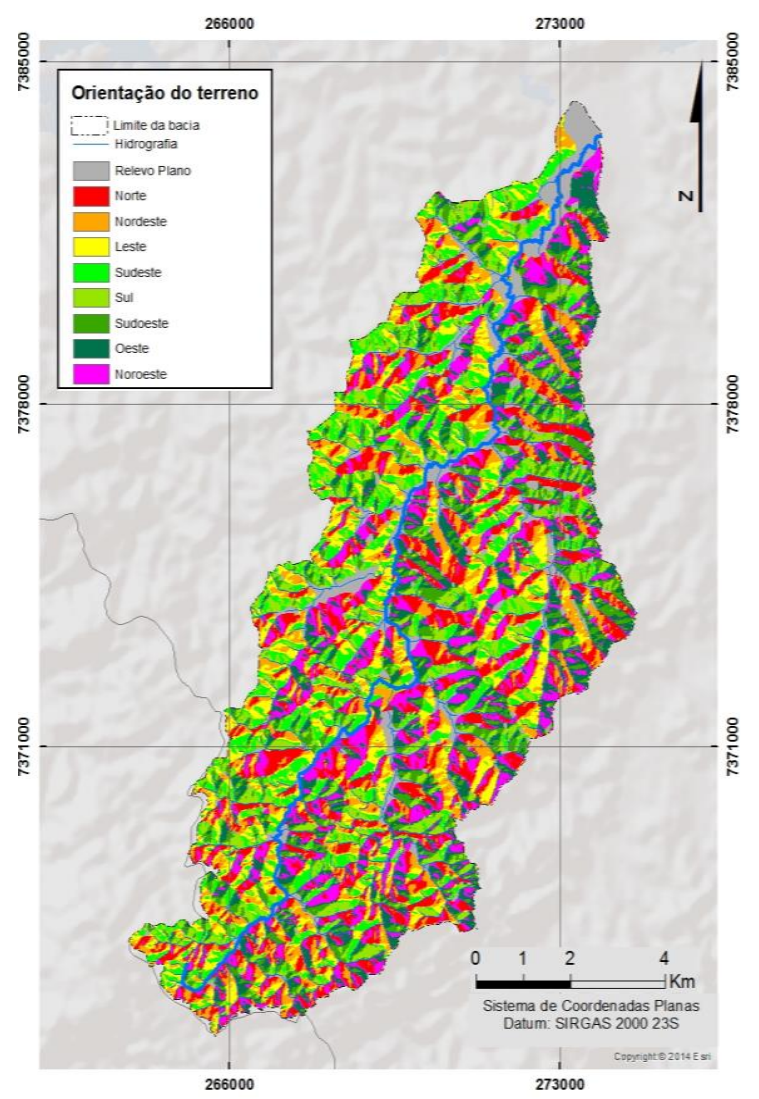

Figura 6: Orientação do terreno da Bacia do rio Una, Ibiúna, São Paulo.

Estudos similares indicam que a orientação do terreno influencia diretamente o quantitativo de vegetação, padrões de precipitação, exposição do terreno ao vento, evapotranspiração e a produtividade de água subterrânea em bacias hidrográficas. Assim, a vertente do relevo é um produto morfométrico e cartográfico que deve ser considerado para a avaliação de processos bióticos e abióticos (MAGESH et al., 2013; MOGHADDAM et al., 2015; RAZANDI et al., 2015).

As bacias com orientação predominante para o hemisfério sul são caracterizadas pelas maior incidência de radiação, com aumento da temperatura e maiores taxas de evapotranspiração. Estas características foram observadas para a bacia estudada e nos estudos 
realizados nas bacias de Córrego Alegre, no Espírito Santo e de Cachoeira das Pombas, Minas Gerais, estando assim, a vegetação influenciada por uma alta taxa de evapotranspiração (FERRARI et al., 2013; TONELLO et al., 2006).

Tabela 7: Quantificação das áreas de orientação do terreno da Bacia do rio Una, Ibiúna, São

\begin{tabular}{l|c|c|c}
\multicolumn{4}{c}{ Paulo } \\
\hline Graus & Orientação & Área (ha) & Área $(\%)$ \\
\hline 0 & Plano & 984,35 & 10,20 \\
\hline Até 22,5 & Norte & 674,71 & 7,00 \\
\hline$>22,5$ até 67,5 & Nordeste & 1170,43 & 12,14 \\
\hline$>67,5$ até 112,5 & Leste & 993,86 & 10,30 \\
\hline$>112,5$ até 157,5 & Sudeste & 1088,19 & 11,30 \\
\hline$>157,5$ até 202,5 & Sul & 954,55 & 9,90 \\
\hline$>202,5$ até 247,5 & Sudoeste & 882,57 & 9,16 \\
\hline$>247,5$ até 292,5 & Oeste & 992,43 & 10,30 \\
\hline$>292,5$ até 337,5 & Noroeste & 1242,65 & 12,90 \\
\hline$>337,5$ até 360 & Norte & 656,16 & 6,80 \\
\hline
\end{tabular}

As características geométricas e da rede de drenagem são apresentadas na Tabela 8.

Tabela 8: Características geométricas e da rede de drenagem da Bacia do rio Una, Ibiúna, São Paulo

\begin{tabular}{l|ll}
\hline \multicolumn{1}{c|}{ Parâmetros } & \multicolumn{2}{c}{ Valores } \\
\hline Área da bacia (A) & 96,42 & $\mathrm{~km}$ \\
\hline Perímetro da bacia (P) & 75,56 & $\mathrm{~km}$ \\
\hline Comprimento da bacia (L) & 19,74 & $\mathrm{~km}$ \\
\hline Largura da bacia & 4,88 & $\mathrm{~km}$ \\
\hline Altitude média da bacia & 937 & $\mathrm{~m} . \mathrm{s} . \mathrm{n} . \mathrm{m}$ \\
\hline Declividade média & 10,61 & graus \\
\hline Declividade média & 18,56 & $\%$ \\
\hline Coeficiente de compacidade (KC) & 2,17 & $\mathrm{adm}$. \\
\hline Indice de circularidade (Ic) & 0,33 & $\mathrm{adm}$. \\
\hline Fator de forma (Kf) & 0,24 & $\mathrm{adm}$. \\
\hline Altitude inicial do curso principal & 1025 & $\mathrm{~m} . \mathrm{s} . \mathrm{n} . \mathrm{m}$ \\
\hline Altitude final do curso principal & 850 & $\mathrm{~m} . \mathrm{s} . \mathrm{n} . \mathrm{m}$ \\
\hline Coeficiente de sinuosidade hidráulico & 1,29 & \\
\hline Densidade da drenagem & 2,14 & $\mathrm{~km} / \mathrm{km}{ }^{2}$ \\
\hline Tempo de concentração & 5,44 & $\mathrm{~h}$ \\
\hline Ordem dos cursos & 5 & ordens \\
\hline Comprimento total do curso & 207,04 & $\mathrm{~km}$ \\
\hline Comprimento do curso principal & 25,5 & $\mathrm{~km}$ \\
\hline Comprimento direto do curso principal & 19,74 & $\mathrm{~km}$ \\
\hline Padrão de drenagem & Dendrítico \\
\hline
\end{tabular}


A bacia apresenta uma área de $96 \mathrm{~km}^{2}$ e perímetro de $75 \mathrm{~km}$. A forma da bacia é irregular e alongada, confirmada pelo Kc alto e pelos baixos valores Ff e Ic, indicando baixa possibilidade de enchentes e baixa concentração do deflúvio em alta precipitação.

O comprimento da bacia equivale a $19,74 \mathrm{~km}$ e largura de $4,88 \mathrm{~km}$, revelando o seu alongamento como uma característica peculiar do tempo de percurso da água e a boa capacidade para recarga de águas subterrâneas, o que não ocorre em bacias curtas (BAJABAA; MASOUD; AMRI, 2013).

A drenagem possui ramificação do tipo dendrítica e padrão sinuoso, já que o coeficiente de sinuosidade aproximou-se do valor de 1. Quanto maior a ramificação da drenagem da bacia, mais eficiente pode ser considerado o seu sistema de drenagem e escoamento máximo, principalmente em áreas altas (BAJABAA; MASOUD; AMRI, 2013; MORISAWA, 1975; STRAHLER, 1957).

O curso principal possui $25,50 \mathrm{~km}$ de extensão e a drenagem total corresponde a 207,04 km. A Figura 7 e a Tabela 9 apresentam as características de comprimento total e o percentual das ordens dos cursos d'água.

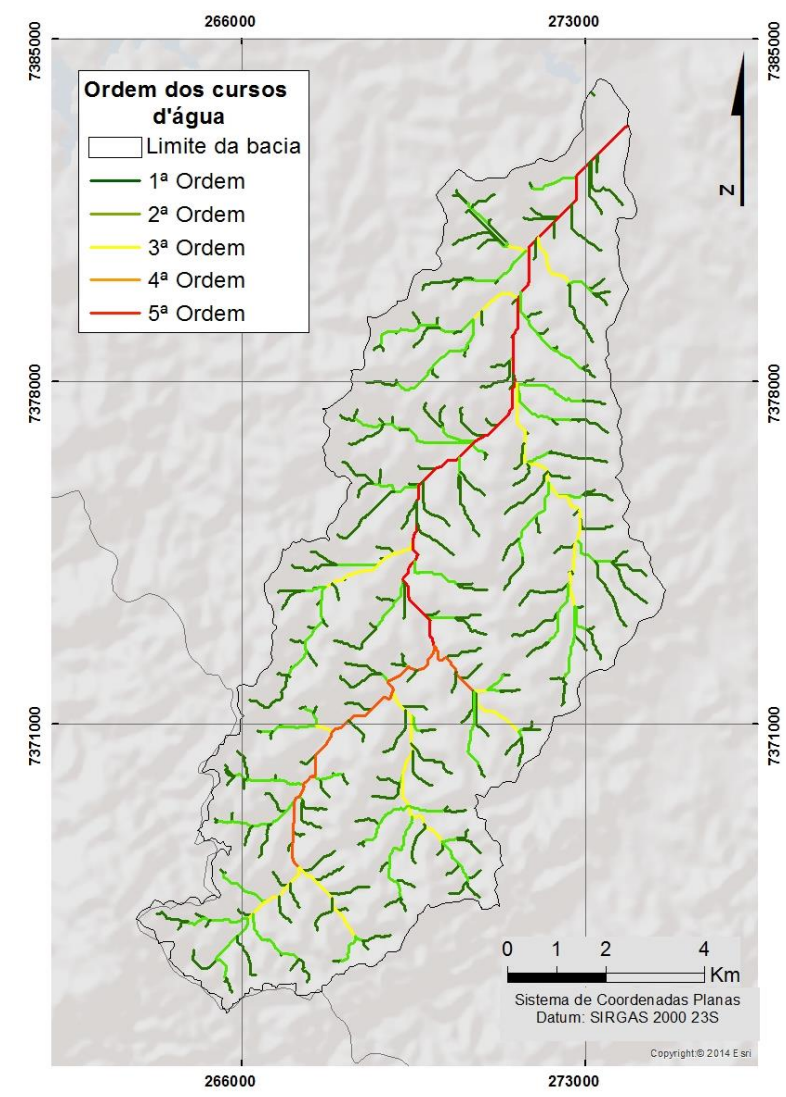

Figura 7 - Ordem dos cursos d'água da Bacia do rio Una, Ibiúna, São Paulo. 
Tabela 9: Comprimento das ordens de cursos d'água da Bacia do rio Una, Ibiúna, São Paulo

\begin{tabular}{c|c|c}
\hline Ordem & Comprimento & \% \\
\hline $1^{\mathrm{a}}$ & $109,9 \mathrm{~km}$ & 53,07 \\
\hline $2^{\mathrm{a}}$ & $56,30 \mathrm{~km}$ & 27,20 \\
\hline $3^{\mathrm{a}}$ & $19,88 \mathrm{~km}$ & 9,60 \\
\hline $4^{\mathrm{a}}$ & $7,95 \mathrm{~km}$ & 3,83 \\
\hline $5^{\mathrm{a}}$ & $13,03 \mathrm{~km}$ & 6,30 \\
\hline
\end{tabular}

Os cursos de primeira ordem representam mais de $50 \%$ do comprimento total da drenagem, aproximando-se de $109 \mathrm{~km}$ de extensão. A área estudada assemelha-se aos achados de Magesh et al. (2013) que também obteve a maior frequência de fluxos de primeira ordem e em áreas de maior altitude, observando uma relação direta entre essas características e a presença de rocha compactada no terreno.

O perfil longitudinal do rio Una é apresentado na Figura 8, com suas respectivas relações entre elevação e distância da água percorrida.

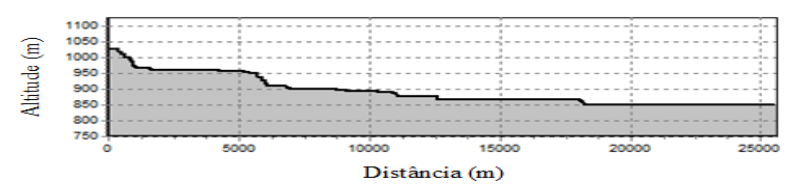

Figura 8: Perfil do curso principal da Bacia do rio Una, Ibiúna, São Paulo.

Observou-se que a elevação é constante no momento em que o rio Una atinge aproximadamente $20 \mathrm{~km}$ de extensão, sendo a altitude inicial do curso principal de $1025 \mathrm{~m}$ e a altitude final de $850 \mathrm{~m}$. A bacia apresenta uma densidade de drenagem correspondente a 2,14 $\mathrm{km} / \mathrm{km}^{2}$, considerada boa, já que drenagens ruins alcançam chegam a alcançar $0,5 \mathrm{~km} / \mathrm{km}^{2} \mathrm{e}$ as bem drenadas correspondem a 3,5 km/km² (VILLELA; MATTOS, 1975).

O tempo de concentração da água até o exutório foi equivalente a 5,44h, deduzindo um tempo entre médio e alto e a direção do fluxo foi identificado do sul para o nordeste. Segundo Ferrari et al. (2013), a bacia tende a ser drenada de acordo com a maior taxa de orientação do terreno. Como a orientação da bacia possui maior percentual para o nordeste, o seu fluxo foi verificado para a mesma direção.

Com relação às características dos solos, a bacia encontra-se situada entre os níveis de ordem de solos do tipo Latossolo e Argissolos. A distribuição espacial das classes pedológicas pode ser observada na Figura 9. 
Os Argissolos representam a classe de solos constituídos por material mineral, profundidade variável, podendo ser forte a imperfeitamente drenados, forte a moderadamente ácidos. A textura varia de arenosa a argilosa no horizonte A, com aumento gradual de agila para o horizonte B. A presença de argila no horizonte B pode ser de baixa atividade textural, ou alta quando saturada por bases e, ainda, caráter alítico (EMBRAPA, 2006).

Os Latossolos representam a classe com estágio avançado de intemperização, profundo, com transições graduais entre os horizontes. Caracterizam-se em solos fortemente a bem drenados, fortemente ácidos, com baixa saturação por bases, distróficos ou alumínicos. Em consequência do teor de chuva, são lixiviados até grandes profundidades e o relevo ocorrente é do tipo plano e suavemente ondulado (BRANCO; CAVINATTO, 1999; EMBRAPA, 2006).

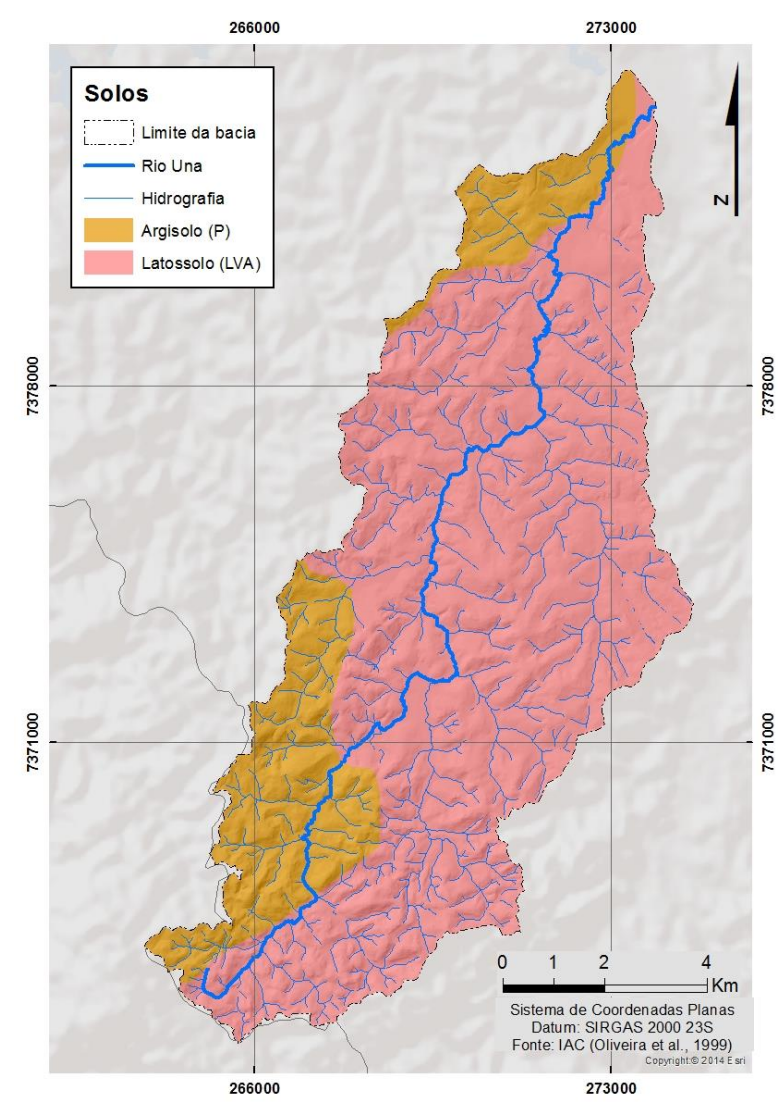

Figura 9: Solos da Bacia do rio Una, Ibiúna, São Paulo.

Quanto aos percentuais de textura destes solos, as características podem ser observadas com a espacialização da Figura 9 e na Tabela 10. 

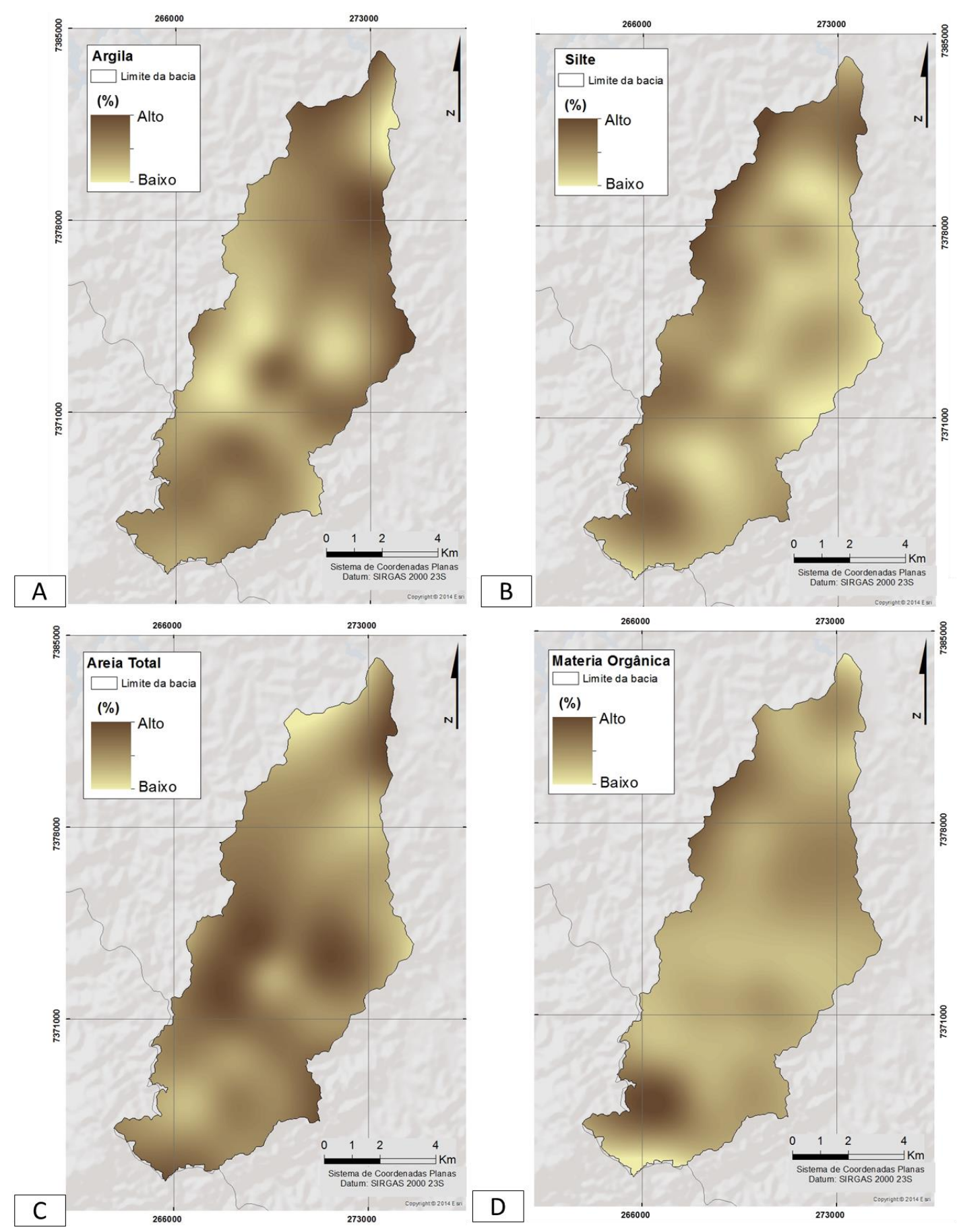

Figura 9: Características pedológicas: [A] Argila. [B] Silte. [C] Areia Total. [D] Matéria Orgânica da Bacia do rio Una, Ibiúna, São Paulo. 
Tabela 10: Percentuais das frações de argila, silte, areia total e matéria orgânica

\begin{tabular}{|c|c|c|c|c|c|c|}
\hline \multirow[b]{2}{*}{ Amostras } & \multicolumn{5}{|c|}{$\%$} & \multirow[b]{2}{*}{$\begin{array}{c}\text { Uso do solo e } \\
\text { Cobertura vegetal }\end{array}$} \\
\hline & Silte & Argila & $\begin{array}{l}\text { Areia } \\
\text { Total }\end{array}$ & Textura & $\begin{array}{l}\text { Matéria } \\
\text { Orgânica }\end{array}$ & \\
\hline 1 & 13,35 & 49,15 & 37,50 & $\bar{A}$ & 19,47 & Comunidade aluvial \\
\hline 2 & 18,15 & 39,70 & 42,15 & FA & 36,81 & Comunidade aluvial \\
\hline 3 & 16,00 & 24,45 & 59,55 & FAA & 10,64 & Floresta Ombrófila Densa \\
\hline 4 & 18,30 & 58,90 & 22,80 & A & 18,08 & Floresta Ombrófila Densa \\
\hline 5 & 7,75 & 57,65 & 34,60 & A & 22,00 & Floresta Ombrófila Densa \\
\hline 6 & 5,82 & 52,78 & 41,40 & A & 27,02 & Cultivos temporários diversificados \\
\hline 7 & 15,50 & 42,53 & 41,98 & A & 42,37 & Floresta Ombrófila Densa \\
\hline 8 & 13,75 & 52,45 & 33,80 & A & 33,00 & Edificações rurais \\
\hline 9 & 11,75 & 43,10 & 45,15 & AA & 22,32 & Cultivos temporários diversificados \\
\hline 10 & 21,30 & 26,10 & 52,60 & FAA & 40,92 & Floresta Ombrófila Densa \\
\hline 11 & 6,95 & 53,95 & 39,10 & A & 40,19 & Edificações rurais \\
\hline 12 & 6,90 & 49,35 & 43,75 & A & 34,37 & Silvicultura \\
\hline 13 & 13,50 & 36,15 & 50,35 & AA & 24,42 & Cultivos temporários diversificados \\
\hline 14 & 11,00 & 46,25 & 42,75 & A & 30,00 & Cultivos temporários diversificados \\
\hline 15 & 11,45 & 27,05 & 61,50 & FAA & 24,22 & Floresta Ombrófila Densa \\
\hline 16 & 11,43 & 29,67 & 58,90 & FAA & 20,23 & Cultivos temporários diversificados \\
\hline 17 & 14,20 & 23,95 & 61,85 & FAA & 21,93 & Floresta Ombrófila Densa \\
\hline 18 & 6,62 & 52,35 & 41,02 & A & 16,95 & Cultivos temporários diversificados \\
\hline 19 & 10,90 & 24,00 & 65,10 & FAA & 14,62 & Floresta Ombrófila Densa \\
\hline 20 & 7,55 & 54,55 & 37,90 & A & 16,65 & Silvicultura \\
\hline 21 & 12,20 & 25,35 & 62,45 & FAA & 15,41 & Floresta Ombrófila Densa \\
\hline 22 & 7.75 & 50,43 & 41,83 & A & 28,62 & Cultivos temporários diversificados \\
\hline 23 & 11,95 & 45,98 & 42,07 & A & 29,68 & Cultivos temporários diversificados \\
\hline 24 & 14,75 & 21,72 & 63,53 & FAA & 23,80 & Floresta Ombrófila Densa \\
\hline 25 & 16,80 & 27,35 & 55,85 & FAA & 14,47 & Cultivos temporários diversificados \\
\hline 26 & 11,08 & 36,72 & 52,20 & AA & 19,20 & Campo degradado \\
\hline 27 & 4,95 & 56,90 & 38,15 & A & 16,73 & Cultivos temporários diversificados \\
\hline 28 & 12,00 & 40,55 & 47,45 & AA & 18,05 & Floresta Ombrófila Densa \\
\hline 29 & 14,17 & 25,47 & 60,35 & FAA & 25,64 & Floresta Ombrófila Densa \\
\hline 30 & 9,65 & 45,00 & 45,35 & AA & 28,07 & Cultivos temporários diversificados \\
\hline 31 & 10,43 & 41,77 & 47,80 & AA & 30,13 & Floresta Ombrófila Densa \\
\hline 32 & 20,45 & 49,75 & 29,80 & A & 67,09 & Floresta Ombrófila Densa \\
\hline 33 & 11,15 & 44,65 & 44,20 & AA & 27,52 & Cultivos temporários diversificados \\
\hline 34 & 16,30 & 38,13 & 45,57 & AA & 32,84 & Cultivos temporários diversificados \\
\hline 35 & 13,05 & 40,80 & 46,15 & AA & 28,47 & Cultivos temporários diversificados \\
\hline
\end{tabular}

Legenda: A - Argilosa. AA - Argilo-arenosa. FA - Franco argilosa. FAA - Franco-argiloarenosa.

A argila variou entre $21 \%$ a $59 \%$, enquanto o silte encontrou-se entre $4 \%$ a $21 \%$, a areia total entre $22 \%$ e $67 \%$ e a matéria orgânica entre $10 \%$ a $67 \%$. Os teores de argila e matéria orgânica apresentaram maior dispersão e heterogeneidade entre os pontos amostrais, quando comparados aos percentuais de silte. 
Conforme a espacialização há uma tendência de maiores percentuais de argila no setor leste, centro-oeste e oeste. A areia total possui distribuição homogênea no território, mas as menores taxas encontram-se ao norte. Para a matéria orgânica, maiores percentuais ao oeste e sudoeste da área foram verificados.

As áreas de florestas e cultivos temporários apresentaram solos com textura que variam entre argilosa a argilo-arenosa. A comunidade aluvial apresentou solos com características argilosa a franco-argilosa, enquanto as edificações rurais e silvicultura apresentaram solos com textura argilosa.

Os tipos de textura encontrados em solos de floresta atlântica são geralmente de argilosa a argilo-arenosa como nos achados (DRUMOND et al., 1996; CUNHA et al., 2007; VALENTE et al., 2011). Em relação aos cultivos temporários e silvicultura sugere-se que pode variar a depender das condições de manejo ou das características do solos locais. A mesma observação referente as propriedade do solo local pode valer para a comunidade aluvial. Porém se outros trabalhos como este forem realizados em bacias com as mesmas características, pode-se fazer uma relação concreta entre o tipo de cobertura e os solos que são predominate encontrados nela.

Quanto à matéria orgânica, esse atributo do solo é originário de resíduos vegetais em decomposição, fragmentos de carvão, substâncias húmicas, biomassa microbiana, além dos compostos orgânicos naturalmente presentes nos solos. Esses materiais conjugam-se aos minerais em porções variadas e representam uma importante fração do solo que deve ser considerada na análise ambiental, não por ser a principal fonte nutriva da cobertura vegetal, mas pela sua capacidade de aumentar a porosidade do solo e por algumas ações de decomposição rápida que geram gás carbônico, água e sais minerais (BRANCO; CAVINATTO, 1999; EMBRAPA, 2006).

Predominou-se valores entre $10 \%$ e $67 \%$ de matéria orgância e uma distribuição bastante diversificada em torno dos usos e cobertura vegetal. As florestas apresentaram a maior variabilidade em termos de matéria orgânica e tende a apresentar cores mais escuras e uma consistência pegajosa, devido ao húmus, que mantém o solo úmido, fixando água e proporcionando boa aderência ao se ligar com as partículas de argila e areia, dificultando a erosão e fixação de sais nutritivos (BRANCO; CAVINATTO, 1999).

A silvicultura e a comunidade aluvial apresentaram pontos com bastante diferença percentual, enquanto os cultivos temporários variaram entre 14 a 32\%. As áreas de cultivos 
agrícolas que apresentam solos com vasta utilização da mecanização e revolvimento ao menos duas vezes ao ano, possuem uma maior capacidade de adensamento e encrosamento, perdendo a sua característica de porosidade, resultado dos baixos percentuais de matéria orgânica observados.

\section{CONSIDERAÇÕES FINAIS}

A bacia hidrográfica do rio Una possui uma dinâmica hidrológica e morfométrica indicativa de baixa ocorrência de enchentes e bom escoamento para o curso principal, sobretudo pelo seu formato irregular e alongado. A rede de drenagem apresenta cinco ordens e uma densidade de drenagem regular e dendrítica. A bacia não apresenta altas taxas de declividade, enquanto a maior orientação do terreno ao nordeste induz o fluxo da água.

O solos Latossolos ou Argissolos possuem maior predominância de usos com textura arenosas e baixos percentuais de silte. A matéria orgância mostrou-se homogênea em todo o território, com maiores percentuais observados em áreas de vegetação natural.

Estas informações culminaram para subsidiar a utilização do território nas áreas agrícolas, tanto no sentido de identificar os percentuais de declive, características de solos e matéria orgânica, como de poder propiciar o conhecimento de características para a recomposição da vegetação natural e orientar a população para o comportamento estrutural na ocorrência de altas precipitações.

\section{AGRADECIMENTOS}

Ao Programa de Pós-Graduação em Ciências Ambientais da UNESP Sorocaba e a Fundação de Apoio ao Instituto de Pesquisas Tecnológicas de São Paulo (FIPT) pelo financiamento da pesquisa e da bolsa de doutorado ao primeiro autor através do Programa Novos Talentos. Ao Centro de Tecnologias Geoambientais, ao Laboratório de Geoprocesssamento e Modelagem Matemática Ambiental, Laboratório de Química e Laboratório de Águas e Solos pela realização das atividades laboratoriais com auxílio das técnicas de laboratório Giovana Maia, Suzan da Silva Lessa e Letícia Boschini Fraga Gonçalves. 


\section{REFERÊNCIAS BIBLIOGRÁFICAS}

AGGIDIS, G.A.; BENZON, D.S. Operational optimisation of a tidal barrage across the Mersey estuary using 0-D modelling. Ocean Engineering, v. 66, 69-81, 2013.

AHER, P.D.; ADINARAYANA, J.; GORANTIWAR, S.D. Quantification of morphometric characterization and prioritization for management planning in semi-arid tropics of India: A remote sensing and GIS approach. Journal of Hydrology, v. 511, p. 850-860, 2014.

BABU, K. J.; SREEKUMAR, S.; ASLAM, A. Implication of drainage basin parameters of a tropical river basin of South India. Applied Water Science, v. 6, n. 67, p. 67-75, 2016.

BAJABAA, S.; MASOUD, M.; Al-AMRI, N. Flash flood hazard mapping based on quantitative hydrology, geomorphology and GIS techniques (case study of Wadi Al Lith, Saudi Arabia). Arabian Journal of Geosciences, v. 7, p. 2469-2481, 2013.

BRANCO, S.M.; CAVINATTO, V.M. Solos - A base da vida terrestre. São Paulo: Moderna. 1999. 79p.

CÂMARA, G.; BARBOSA, C.C.F.; DAVIS, C.; FONSECA, F. Conceitos básicos em geoprocessamento. In: Câmara, G.; Barbosa, C. C. F.; Davis C.; Fonseca F. Geoprocessamento: teoria e aplicações. São José dos Campos: INPE, 1999.

CLARK LABS. Idrisi Selva. Worcester: Clark Labs, Clark University. 2012.

CUNHA e SILVA, D. C.; ALBUQUERQUE FILHO, J. L.; SALE, J. C. A.. LOURENÇO, R. W. Uso de indicadores morfométricos como ferramentas para avaliação de bacias hidrográficas. Revista Brasileira de Geografia Física, v. 9, n. 2, p. 627-642, 2016.

DRUMOND, et. al. Alterações Fitossociológicas e Edáficas na Mata Atlantica em Função das Modificações das Cobertura Vegetais. Rev. Arvore, Viçosa, v. 20, n. 4, p. 451-466, 1996.

CUNHA, G. M. et al. Fósforo Orgânico em Solos Sob Florestas Montanas, Pastagens e Eucalipto no Norte Fluminense. Revista Brasileira de Ciência do Solo, v. 31, n. 4, p. 667672, 2007.

EMBRAPA. Centro Nacional de Pesquisa de Solos (Rio de Janeiro, RJ). Sistema brasileiro de classificação de solos. 2. ed. - Rio de Janeiro : EMBRAPA-SPI, 2006. 306 p.

ESRI. ECONOMIC AND SOCIAL RESEARCH INSTITUTE. ArcGIS. 2014.

FERRARI, J. L.; SILVA, S.S.F.; SANTOS, A.R.; GARCIA, R.F. Análise morfométrica da sub-bacia hidrográfica do córrego Horizonte, Alegre, ES. Revista Brasileira de Ciências Agrárias, v. 8, n. 2, p. 181-188, 2013.

IAC. INSTITUTO AGRONÔMICO DE CAMPINAS. Boletim técnico 106 - Métodos de análise química, mineralógica e física de solos. Campinas: IAC, 2009. 77p.

KIRPICH, Z.P. Time of concentration of small agricultural watersheds. Civil Engineering, v. 10, n. 6, p. 362, 1940.

MAGESH N. S; CHANDRASEKAR, N.; KALIRAJ, S. A GIS based automated extraction tool for the analysis of basin morphometry. Bonfring International Journal of Industrial Engineering and Management Science, v. 2, n.1, p. 32-35, 2012.

MAGESH, N. S.; JITHESHLAL, K.V.; CHANDRASEKAR, N.; JINI, K.V. Geographical information system-based morphometric analysis of Bharathapuzha river basin, Kerala, India. Applied Water Science, v. 3, p. 467-477, 2013.

MESA, L. M. Morphometric analysis of a subtropical Andean basin (Tucuman, Argentina). Environmental Geology, v. 50, n. 8, p. 1235-1242, 2006.

MOGHADDAM, D. D.; REZAEI, M.; POURGHASEMI, H.R. POURTAGHIE, Z. S.; PRADHAN, B.. Groundwater spring potential mapping using bivariate statistical model and 
GIS in the Taleghan Watershed, Iran. Arabian Journal of Geosciences, v. 8, p. 913-929, 2015.

MORISAWA, M. Tectonics and geomorphic models. In: MELHORN, W. N.; FLEMAL, R. C.(edits.). Theories of landform development. London: G. Allen \& Unwin, 1975. p.199216.

MUlUGETA, D.; SHELEME, B. Characterization and Classification of Soils along the Toposequence of Kindo Koye Watershed in Southern Ethiopia. East African Journal of Sciences, v. 4, n. 2, p. 65-77, 2010.

NAUTIYAL, M.D. Morphometric analysis of drainage basin using aerial photographs: a case study of Khairkuli basin, District Dehradun, U.P. J. Journal of the Indian Society of Remote Sensing, v. 22, n. 4, p. 251-261, 1994.

OLIVEIRA, J.B. Mapa pedológico do Estado de São Paulo. Escala 1:500.000 Campinas: Instituto Agronômico de Campinas, 1999.

RAZANDI, Y; POURGHASEMI, H.R.; NEISANI, N.S.; RAHMATI, O. Application of analytical hierarchy process, frequency ratio, and certainty factor models for groundwater potential mapping using GIS. Earth Science Informatics, v. 8, p. 867-883, 2015.

SANTOS, A.R. (Org.) ArcGIS 9.3® total: Aplicações para dados espaciais. Alegre, ES: CAUFES, 2010. 184p.

SHELEME, B. Characterization of soils along a toposequence in Gununo area, southern Ethiopia. Journal of Science and Development, v. 1, n. 1, p. 31-41, 2011.

STRAHLER, A.N. Quantitative analysis of watershed geomorphology. Transactions of the American Geophysical Union, v. 38, n. 6, p.913-920, 1957.

TONELLO, K.C.; DIAS, H.C.T.; SOUZA, A.L.; RIBEIRO, C.A.A.S.; LEITE, F.P. Morfometria da bacia hidrográfica da Cachoeira das Pombas, Guanhães - MG. Revista Árvore, v. 30, n. 5, p. 849-857, 2006.

VALENTE, A. S. M. Composição, estrutura e similaridade florística da Floresta Atlântica, na Serra Negra, Rio Preto - MG. Rodriguésia, v. 62, n. 2, p. 321-340. 2011

VAlERIANO, M. M.; ALBUQUERQUE, P. C G. Topodata: processamento dos dados SRTM. São José dos Campos: INPE, 2010. 79p.

VILLELA, S.M.; MATTOS, A. Hidrologia aplicada. São Paulo: McGraw-Hill do Brasil, 1975. 245p.

Recebido em 28 de agosto de 2017. Aceito em 11 de outubro de 2017. 